\title{
Health facility readiness to care for high risk newborn babies for early childhood development in eastern Uganda
}

Gertrude Namazzi ${ }^{1,2^{*}}$, Helena Hildenwall ${ }^{3,4,5}$, Grace Ndeezi ${ }^{6}$, Paul Mubiri ${ }^{1}$, Christine Nalwadda ${ }^{7}$, Angelina Kakooza-Mwesige ${ }^{6}$, Peter Waiswa ${ }^{1}$ and James K. Tumwine ${ }^{6,8}$

\begin{abstract}
Background: The neonatal mortality rate in Uganda has barely changed over the past decades, estimated at 28/1000 and 27/1000 live births in 2006 and 2016 respectively. The survivors have a higher risk of developing neurodevelopmental disabilities (NDD) due to brain insults from perinatal complications related to poor quality of health services during pregnancy, around the time of birth, and during the postnatal period. This study aimed to assess health facility readiness to care for high risk newborn babies in order to inform programming that fosters early childhood development in eastern Uganda.
\end{abstract}

Methods: A cross sectional study of 6 hospitals and 10 higher level health centers that offer comprehensive maternal and newborn care was carried out in February 2020 in eastern Uganda. A World Health Organization Service Availability and Readiness Assessment tool (SARA) was adapted and used to assess the health facility readiness to manage maternal and neonatal conditions that are related to NDD. In addition, 201 mothers of high risk newborn babies were interviewed on their satisfaction with health services received. Readiness scores were derived from percentage average facilities with available infrastructure and essential medical commodities to manage neonatal complications. Descriptive statistics were computed for client satisfaction with service provision, and p values used to compare private not for profit to public health facilities.

Results: There was limited availability in numbers and skilled human resource especially the neonatal nurses. Hospitals and health centers scored least in preterm and hypothermia care, with averages of 38\% and 18\% respectively. The highest scores were in essential newborn care, with readiness of $78 \%$ and $85 \%$ for hospitals and health centers, followed by resuscitation at 78\% and 77\%, respectively. There were no guidelines on positive interaction with newborn babies to foster neurodevelopment. The main cause of admission to neonatal care units was birth asphyxia followed by prematurity, indicative of intrapartum care challenges. The overall client satisfaction with health services was higher in private not for profit facilities at 91\% compared to public hospitals at 73\%, $p=0.017$.

Conclusion: Health facility readiness was inadequate in management of preterm complications. Efforts should, therefore, be geared to improving availability of inputs and quality of emergency obstetric and newborn care in order to manage high risk newborns and reduce the burden of NDD in this setting.

\footnotetext{
*Correspondence: namazzi_ge@yahoo.co.uk

${ }^{1}$ Department of Health Policy, Planning and Management, School

of Public Health, College of Health Sciences, Makerere University, Mulago

Hill Road, P. O. Box 7072, Kampala, Uganda

Full list of author information is available at the end of the article
} original author(s) and the source, provide a link to the Creative Commons licence, and indicate if changes were made. The images or other third party material in this article are included in the article's Creative Commons licence, unless indicated otherwise in a credit line to the material. If material is not included in the article's Creative Commons licence and your intended use is not permitted by statutory regulation or exceeds the permitted use, you will need to obtain permission directly from the copyright holder. To view a copy of this licence, visit http://creativecommons.org/licenses/by/4.0/. The Creative Commons Public Domain Dedication waiver (http://creativeco mmons.org/publicdomain/zero/1.0/) applies to the data made available in this article, unless otherwise stated in a credit line to the data. 
Keywords: Neurodevelopment, Facility readiness, High risk newborns, Essential newborn care, Birth asphyxia, Preterm

\section{Background}

Globally, 2.5 million newborn babies die annually due to preventable causes [1]. Complications of birth including prematurity and low birth weight (LBW), Hypoxic Ischemic Encephalopathy/asphyxia, and neonatal sepsis account for $80 \%$ of all neonatal deaths. The survivors are at risk of neurodevelopmental disability (NDD) $[2,3]$. NDDs are characterized by deficits in one or a combination of the following domains during the early period of a child's growth: motor, and sensory functionality, attention, socio-emotional behavior, memory, and language [4]. The period from pregnancy to three years is the most critical phase for child brain development. Nurturing care that ensures early child development starts before birth and comprises of: health, nutrition, security and safety, responsive caregiving, and opportunities for early learning. The quality of health service provision and a supportive environment are pivotal to neurodevelopment during pregnancy, childbirth and postnatal period $[5,6]$.

Over $80 \%$ of the global birth complications occur in low income countries (LICs) with very limited access to neonatal intensive care units and well equipped special newborn care units (SNCU) [7]. Yet well-functioning newborn care units would save over $70 \%$ of newborn deaths and prevent disabilities due to prematurity and birth complications [8]. The majority of NDDs are related to insults due to poor quality of health services during pregnancy, around time of birth, and during the postnatal period [9]. Improvements in quality of maternal and newborn health services provided at health facility level, coupled with follow-up care is critical for early childhood development (ECD) and hence human capital productivity [5].

Small and sick newborn babies/high risk babies (HRB) require provision of timely quality services including feeding, warmth for the low birth weight (LBW) and preterms, phototherapy and safe oxygen support in case of hypoxemia [7]. Some of the recommended high impact and cost effective neonatal interventions for low resource settings include Kangaroo Mother Care (KMC) and Helping Babies Breath (HBB) [10-12]. KMC, if immediately initiated at the health facility and continued after discharge, was found to be beneficial in curbing NDD [13]. In addition, HRB should be protected from acquiring infections, and effective and adequate treatment with parenteral antibiotics where infection occurs. However, coverage of effective interventions is still limited [14], and health system bottlenecks limit the quality of services provided to the vulnerable newborn babies in LIC setting.

There is evidence that health facility contextual factors are influential in the level of quality of care $(\mathrm{QoC})$ provided [16]. The Donabedian quality of care framework considers three components including the structure/inputs, processes, and health care outcomes [17]. Adequate knowledgeable and skilled health workers, availability of essential medicines and equipment, and an enabling/motivating environment are particularly important in saving the HRBs as well as preventing disabilities and enabling the vulnerable infants to thrive [5]. Major constraints in the workforce, financing, and service delivery for maternal and newborn care in LICs were reported by previous scholars [18-21]. For instance, in LICs the average nurse/midwife ratio per 10,000 population is only 7 compared to 57 in developed countries [7]. The limited numbers of, and skilled staff result in suboptimal maternal and newborn care which is unable to foster early child development [22, 23]. For example, a significant proportion of newborn babies in LICs have delayed breastfeeding, poor cord care, and are not assessed for potential danger signs before discharge following birth [24]. Quality of care gaps in resource constrained settings must therefore be addressed to realize reduction in neonatal deaths and ensure those that survive do thrive and attain their full developmental potential $[25,26]$.

In Uganda, while the policy environment is conducive for improved quality of care for the newborn, translation into practice is still a big challenge that requires better understanding of barriers in order to design contextually appropriate interventions [27] for not only newborn survival but for proper growth and development [28]. Although institutional deliveries in Uganda have increased from $42 \%$ in 2006 to $73 \%$ in 2016, this has not translated into reduction of neonatal mortality estimated to be $28 / 1000$ in 2006 and $27 / 1000$ live births in 2016 [29, 30]. Recent studies also indicate that there is a high prevalence of NDD in the country, and most of the associated factors including asphyxia, post-neonatal complications, and malnutrition among preterm infants are preventable $[13,31]$. There is currently an increased scale up of neonatal care units in the country but the quality of care provided for management of HRBs to prevent mortality and NDD is not clear. This study therefore, aimed at assessing health facility readiness to care for high risk newborn babies in order to inform programming that fosters early childhood development in eastern Uganda. 


\section{Methods}

\section{Study Design and Setting}

A cross sectional study was carried out in February 2020 in six hospitals and ten higher level health centers ( $\mathrm{HC}$ IVs) in Busoga region in eastern Uganda. This was before the first Covid-19 case had been identified in the country. In Uganda Health Centres (HC) vary in their care provision across three levels - HC II, HC III, and HC IV. The higher level HC IVs offer comprehensive maternal and newborn care for HRBs. Busoga region has a population of about four million people, with a NMR estimated at $30 / 1000$ live births in 2015 [32]. The region is served by eleven hospitals [33].

The hospitals included in this study were 4 public and 2 'private not for profit' health facilities (PNFP). All the HCIVs were government owned health facilities. One of the public hospitals was a regional referral hospital to which the rest of the general hospitals refer complicated cases. All the six hospitals were sites for the Preterm Birth Initiative (PTBi) study which was conducted between 2016 and 2019. The PTBi study aimed at reducing preterm morbidity and mortality through four intervention components: Data strengthening, use of the modified WHO Safe Childbirth Checklist, health provider training and mentorship, and use of collaborative quality improvement approach [34]. The PTBi study also provided some equipment and supplies at the start of implementation to address the critical gaps identified during the baseline study.

In the current study, the facilities were assessed to determine their readiness for care of HRBs: availability of inputs based on standards and clients' experiences of the maternal and newborn care received. The health facilities were selected on the basis of being high volume facilities that are mandated to offer emergency obstetric and newborn care. We selected public and PNFP hospitals, and health centers IVs. This allowed us to assess the facility readiness based on the variation of the type of facilities in the region.

\section{Data collection}

The WHO Services Availability and Readiness Assessment (SARA) tool, previously used by the PTBi study, was adapted based on the matrix developed by Moxon et al. 2018 [35], and used to assess the readiness of included facilities to care for HRBs. The adaptation of the SARA tool involved adding infrastructure for thermoregulation beyond KMC, and management of jaundice, use of a continuous positive airway pressure (CPAP) ventilation, and neurodevelopmental support. The inputs for neurodevelopmental support included: availability of cyclic lights, sound control measures, and guidelines for positive interactions with newborns and communication with carers. The infrastructure assessed included space for special care and resuscitation, stabilization and KMC. The staffing levels and availability of the skilled cadres were determined. An inventory was taken of equipment and commodities including nasal gastric tubes for feeding, availability of antibiotics for treatment of neonatal bacterial infection, intravenous fluids, oxygen, use of pulse oximetry, and use of a phototherapy machine for effective case management of pathological jaundice. The inventory data were collected by the first author, with the support of one research assistant, using a paper checklist written in English.

The experience of service provision for HRBs from the client perspective was assessed through client exit interviews in the hospitals. The HRBs were defined as: babies with APGAR score of less than 7 five minutes after birth, preterms with a gestation age of less than 37 weeks at birth, babies with a birth weight of less than $2500 \mathrm{~g}$ at birth, and infections characterized by either convulsions, failure or cessation of feeding, fast breathing of $>60$ breaths per minute, severe chest in-drawing, temperature $>37.5{ }^{\circ} \mathrm{C}$ or $<35.5{ }^{\circ} \mathrm{C}$, movement only when stimulated or no movement at all. Additionally, HRBs included those with pathological jaundice: a condition where a term newborn baby presents with jaundice within $24 \mathrm{~h}$ after birth, or the total serum bilirubin level is higher than $17 \mathrm{mg} / \mathrm{dl}$ in infants 25 to $48 \mathrm{~h}$ old, and the infant has signs and symptoms of serious illness. On average, $250 \mathrm{HRBs}$ were admitted in the SNCU on a monthly basis from the six hospitals [36]. After excluding 10 runaway cases, 14 patients referred to other facilities and 25 deaths, 201 mothers with HRBs were included in the study. Proportionate to size sampling methods were used to distribute the sample size across the six hospitals.

Six research assistants with medical background who were trained for two days and supervised by the first author, were attached to the hospitals (one per hospital) for a month. The research assistants liaised with the nurses working in the maternity and special newborn care units of the respective hospital and were informed of the potential discharges to enable interviews to be conducted immediately after discharge. On discharge, mothers with HRBs were interviewed on the care their babies received and how it was provided using the exit interview tool in Lusoga, the local language. Satisfaction with the services mothers received was captured by questions regarding the attitude of health providers, consultation time given to them, waiting time, general cleanness of the premises and on specific care during the delivery and postnatal period. In addition, mothers were asked whether they were given information on how to care for their babies after discharge, any counselling on danger signs and feeding, and details on when to come back for 
review of the babies. We ensured that participants did not wait for more than 10 min before interviews following discharge from the SNCU.

\section{Data management and analysis}

Facility readiness to manage maternal and neonatal conditions that result in NDD was determined by the availability of infrastructure, medical commodities, skilled providers and client satisfaction with service provision. These were based on the list of evidence-based treatments (inclusive of items for diagnosis, treatment, and monitoring) for the common neonatal conditions developed by Morgan and team (essential routine newborn care; neonatal resuscitation; feeding and hypothermia; respiratory distress/apnea of prematurity; infection, convulsions and jaundice) [20], and on the WHO quality of care standards on developmental support for sick and small newborn babies [6]. Neonatal complications are known to be the main causes of neonatal deaths and also responsible for neonatal developmental disabilities among survivors. In addition, availability of resources for antenatal and emergency obstetric care (EmOC) were included given their critical role in neonatal survival and developmental potential during prenatal and intrapartum period.

Data from the SARA tool and exit interviews were entered in ACCESS with consistence checks and later exported to STATA version 15 for analysis. Descriptive statistics using frequencies, percentages, means, and standard deviations were used to summarize the data stratified by type of facility. Readiness scores were derived from proportions of facilities with availability of essential equipment, supplies and medicines for care of HRBs. The scores were then compared across the public hospitals, PNFP, and HCIV facilities.

The satisfaction of mothers of HRBs was assessed on several services received. We considered satisfaction to include those who mentioned 'very satisfied' and 'satisfied' for each variable. Chi square test statistic was computed to determine whether there was any difference in satisfaction between the Public and PNFP hospitals.

\section{Ethical considerations}

Ethical approval to conduct the study was obtained from the Higher Degrees and Research Ethical Committee (HDREC) of Makerere University School of Health Sciences (Ref. 2017- 011) and Uganda National Council of Science and Technology (\#SS4600). Permission to access the health facilities was obtained from the district health authorities and the hospital administration prior to facility assessment and exit interviews. Written informed consent was obtained from all mothers of HRBs before data collection.

\section{Results}

\section{Health facility characteristics}

All the six hospitals were conducting deliveries $24 \mathrm{~h}$ a day, with capacity to do a caesarian section and with a neonatal special care unit including a dedicated unit for KMC. Although all the HCIVs were conducting deliveries $24 \mathrm{~h}$ a day only six were able to carry out Caesarian sections, two were unable due to inadequacies of theatre, while another two lacked anesthetists and relied on medical officers for giving anesthesia. All the health facilities had basic amenities such as electricity and running water. The average monthly deliveries were more at the public hospitals (450) than at the PNFP (79) and HCIVs (106) (Table 1). All the health facilities had medical officers attached to maternity and SNCU units, but only the regional referral hospital and the high volume district level hospital had obstetricians and pediatricians. The clinical officers at hospital level were only attached to the general outpatient department and did not work in the antenatal or maternity units, while at HCIV they could work in other inpatient departments rather than maternity. There was only one neonatal nurse based at the regional referral hospital. The rest of the health facilities had midwives that run the NSCU, and these were also the same midwives that conducted deliveries in the general hospitals and HCIVs. The average monthly number of HRBs admitted in the public hospitals was $61 \mathrm{com}$ pared to 15 in the PNFP, and 12 in HCIVs. There were no guidelines in any facility for positive interactions with the HRBs and for communication with the caregivers on how to ensure proper neurodevelopment of the vulnerable newborn babies.

\section{Goal oriented antenatal care and delivery care}

Readiness for provision of ANC was high in HCIVs (83\%) but generally low in hospitals with an average score of $58 \%$ (Table 2). The readiness was lower in public health facilities due to lack of access to ultrasonography at the facilities during pregnancy, lack of examination/flash light, and limited availability of diagnostic equipment particularly for hemoglobin and blood sugar level estimation. Two (50\%) of the public health facilities did not have a single functioning blood pressure machine in the antenatal departments, only one out of the four public hospitals had stock of ferrous sulphate tablets, and one had run out of stock of folic acid tablets.

The readiness average scores for EmOC and blood transfusion services were $70 \%$ in hospitals and $74 \%$ in HCIVs (Table 2). However, there were limitations in availability of oxygen, found in only 2 public hospitals and pulse oximeters were available in only one public hospital. Similarly, there was lack of access to ultrasound 
Table 1 Health facility characteristics: utilization, infrastructure and human resource

\begin{tabular}{|c|c|c|c|c|c|}
\hline Characteristics & Items/requirements & $\begin{array}{l}\text { Public Hospitals } \\
n=4\end{array}$ & $\begin{array}{l}\text { PNFPs } \\
\text { Hospitals } \\
n=2\end{array}$ & $\begin{array}{l}\text { All Hospitals } \\
n=6(\%)\end{array}$ & $\begin{array}{l}\text { HCIVs } \\
\text { (Public) } \\
n=10 \text { (\%) }\end{array}$ \\
\hline \multicolumn{6}{|l|}{ Infrastructure } \\
\hline & Dedicated KMC unit with amenities for rooming in & 4 & 2 & $6(100)$ & $4(40)$ \\
\hline & Running water & 4 & 2 & $6(100)$ & $8(80)$ \\
\hline & Soap/disinfectant & 4 & 2 & $6(100)$ & $10(100)$ \\
\hline & Electricity & 4 & 2 & $6(100)$ & $10(100)$ \\
\hline \multicolumn{6}{|c|}{ Average monthly health facility utilization } \\
\hline & ANC & 1,179 & 388 & 915 & 431 \\
\hline & Delivery & 450 & 79 & 326 & 106 \\
\hline & HRB (Small \& Sick newborn) admissions to the NSCU & 61 & 15 & 45.7 & 12 \\
\hline Staffing/Human Resource & $\begin{array}{l}\text { Attached to antenatal, maternity, Postnatal, NSCU } \\
\text { and peadiatric ward }\end{array}$ & & & & \\
\hline \multirow[t]{2}{*}{ Numbers } & Obstetricians & 3 & 0 & 3 & \\
\hline & Peadiatricians & 3 & 0 & 3 & \\
\hline \multirow[t]{5}{*}{ Average number } & Medical Officers & 5 & 3.5 & 4.6 & 2 \\
\hline & Anesthetists & 2.8 & 1.5 & 2.3 & 0.4 \\
\hline & Midwives & 12.3 & 10 & 11.5 & 6.1 \\
\hline & Nurses/midwives attached to NSCU & 2.8 & 1.4 & 2.3 & 00 \\
\hline & NSCU Nurse to newborn ratio & $1: 21$ & $1: 11$ & $1: 20$ & 00 \\
\hline \multicolumn{6}{|c|}{ Developmental supportive care } \\
\hline & $\begin{array}{l}\text { Guidelines on Positive interactions with newborns } \\
\text { and communication with carers }\end{array}$ & 00 & 00 & 00 & 00 \\
\hline
\end{tabular}

scan, which was only available in one general high volume hospital and four of HCIVs. Although resuscitation tables for newborn babies existed in all the health facilities, they lacked overhead heaters. The resuscitation algorithm and referral protocols were available in most (70\%) of the HCIVs but in only two (50\%) of the public hospitals while both PNFP hospitals did not have referral protocols.

\section{Essential routine newborn care and resuscitation}

Readiness scores for essential routine newborn care were higher in HCIVs (85\%) compared to hospitals at $78 \%$ (Table 3). However, the readiness for resuscitation was not so different in the hospitals (78\%) and in HCIVs (77\%). Only two hospitals (one PNFP and one public) had umbilical cord ties. Most health facilities were improvising by using the end parts of gloves as cord ties. The resuscitation area lacked a heat source in half of hospitals and HCIVs. Similarly, only half of the hospitals had the pulse oximeters with accompanying probes.

Infection control, management and convulsions readiness Overall, the average score for infection control, management + convulsions readiness was $60 \%$ in hospitals, public and PNFP facilities, and about 50\% in HCIVs (Table 3 ). None of the health facilities assessed had chlorhexidine for cord care to prevent infection, and none of the facilities had C-reactive protein tests for assessing the possibility of infection. Similarly, all the facilities had no neonatal lancets for taking off blood for laboratory testing. They were using ordinary needles to prick the neonates. Gentamycin, an essential first line antibiotic for treatment of neonatal septicemia, was out of stock in all public hospitals. Only two high volume public hospitals had the multi-functional monitors to monitor the vital functions of sick newborn babies. None of the health facilities had an infusion pump, and only two public facilities had burettes for controlled provision of intravenous fluids, and dextrose (Table 3). None of the HCIVs had readily available $10 \%$ dextrose for treatment of hypoglycemia, and also lacked 50\% dextrose to enable preparation locally.

\section{Hypothermia and preterm care}

Readiness of all health facilities was poorest regarding preterm and hypothermia care. The overall average score was $38 \%$ for hospitals and $18 \%$ for HCIVs (Table 3 ). The poor score was due to limited facilities for sound and light control, lack of surfactant, and KMC beds or chairs. Only the referral hospital had one KMC bed provided by the KMC study. The rest of the health facilities were using ordinary beds and plastic chairs for mothers to 
Table 2 Antenatal care and EmOC guidelines, supplies and medicines

\begin{tabular}{|c|c|c|c|c|c|}
\hline Stage of care & Items/requirements & $\begin{array}{l}\text { Public hospitals } \\
n=4\end{array}$ & $\begin{array}{l}\text { PNFPs Hospitals } \\
n=2\end{array}$ & $\begin{array}{l}\text { All hospitals } \\
n=6(\%)\end{array}$ & $\begin{array}{l}\text { HCIVs } \\
n=10 \\
n(\%)\end{array}$ \\
\hline \multicolumn{6}{|l|}{ Antenatal care } \\
\hline & Guidelines & 3 & 2 & $5(83.3)$ & $7(70)$ \\
\hline & Visual aids for counselling & 4 & 2 & $6(100)$ & $9(90)$ \\
\hline & Adult weighing scale & 4 & 2 & $6(100)$ & $10(100)$ \\
\hline & Blood Pressure machine & 2 & 2 & $4(67)$ & $9(90)$ \\
\hline & Ferrous sulphate & 1 & 2 & $3(50)$ & $10(100)$ \\
\hline & Folic acid & 3 & 2 & $5(83.3)$ & $10(100)$ \\
\hline & Oral Antibiotics (Amoxycillin, etc.) & 4 & 2 & $6(100)$ & $9(100)$ \\
\hline & Intermittent Preventive Therapy (Fansidara ${ }^{a}$ ) & 3 & 2 & $5(83.3)$ & $10(100)$ \\
\hline \multirow[t]{12}{*}{ Antenatal care } & Diagnostics (for syphilis, malaria, blood sugar, Urine tests) & & & & \\
\hline & Syphilis testing & 3 & 2 & $5(83.3)$ & $10(100)$ \\
\hline & Malaria testing & 4 & 2 & $6(100)$ & $10(100)$ \\
\hline & Urine protein test & 2 & 0 & $2(33.3)$ & $8(80)$ \\
\hline & Urine Glucose test & 2 & 0 & $2(33.3)$ & $9(90)$ \\
\hline & Blood glucose test & 1 & 0 & $1(16.7)$ & $8(80)$ \\
\hline & Any rapid test for hemoglobin & 1 & 0 & $1(16.7)$ & $9(90)$ \\
\hline & Ultrasonography & 0 & 2 & $2(33.3)$ & $2(20)$ \\
\hline & Examination light (flashlight) & 0 & 0 & $0(00)$ & $5(50)$ \\
\hline & Fetal doppler & 1 & 1 & $2(33.3)$ & $7(70)$ \\
\hline & Thermometer & 1 & 2 & $3(50.0)$ & $8(80)$ \\
\hline & Visual privacy only & 1 & 1 & $2(33.3)$ & $8(80)$ \\
\hline \multirow{22}{*}{$\begin{array}{l}\text { Overall mean score } \\
\text { EmOC }\end{array}$} & ANC & $2.1(52.5)$ & $1.4(68.4)$ & $3.4(58.3)$ & $8.3(83)$ \\
\hline & & & & & \\
\hline & $\begin{array}{l}\text { Guidelines for emergencies (Pre/Eclampsia, Postpartum hemor- } \\
\text { rhage, etc.) }\end{array}$ & 3 & 2 & $5(83.3)$ & $9(90)$ \\
\hline & Partographs for monitoring labor & 4 & 2 & $6(100)$ & $10(100)$ \\
\hline & Oxytocin to augment labor & 3 & 2 & $5(83.3)$ & $9(90)$ \\
\hline & Items available and functioning in the delivery area & & & & \\
\hline & Ultrasound machine & 1 & 0 & $1(16.7)$ & $4(40)$ \\
\hline & Blood pressure cuff & 4 & 2 & $5(83.3)$ & $9(90)$ \\
\hline & Resuscitation table with heat source & 2 & 1 & $3(50.0)$ & $3(30)$ \\
\hline & Pulse oximeter with neonatal probe & 2 & 0 & $1(16.7)$ & $5(50)$ \\
\hline & Filled oxygen canisters & 1 & 0 & $1(16.7)$ & $5(50)$ \\
\hline & Infant weighing scale & 2 & 1 & $3(50.0)$ & $9(90)$ \\
\hline & Suction bulb & 4 & 2 & $6(100)$ & $9(90)$ \\
\hline & Soap or hand disinfectant & 3 & 2 & $5(83.3)$ & $10(100)$ \\
\hline & IV/IM Antibiotics & 4 & 2 & $6(100)$ & $8(80)$ \\
\hline & IM/IV Magnesium Sulphate (anticonvulsant) & 3 & 2 & $5(83.3)$ & $8(80)$ \\
\hline & Antihypertensive e.g. hydralazine & 4 & 2 & $6(100)$ & $5(50)$ \\
\hline & Vacuum extractor-for assisted delivery & 2 & 1 & $3(50)$ & $5(50)$ \\
\hline & $\begin{array}{l}\text { Ability to do surgery (C/S): MO/OBGY, Theatre, Anesthetics, } \\
\text { Surgical instruments, etc }\end{array}$ & 4 & 2 & $6(100)$ & $8(80)$ \\
\hline & Blood transfusion & 4 & 2 & $6(100)$ & $8(80)$ \\
\hline & Referral protocols & 2 & 0 & $2(33.3)$ & $9(90)$ \\
\hline & Resuscitation algorithm & 2 & 2 & $4(66.7)$ & $7(70)$ \\
\hline Overall mean score & EmOC + Blood transfusion & $2.8(71.1)$ & $1.4(71.1)$ & $4.2(70.0)$ & $7.4(74)$ \\
\hline
\end{tabular}


Table 3 Postnatal care including resuscitation, feeding and infection control, supplies and medicines

\begin{tabular}{|c|c|c|c|c|c|}
\hline Immediate PNC & Items/requirements & $\begin{array}{l}\text { Public hospitals } \\
n=4\end{array}$ & $\begin{array}{l}\text { PNFPs hospitals } \\
n=2\end{array}$ & $\begin{array}{l}\text { All hospitals } \\
n=6(\%)\end{array}$ & $\begin{array}{l}\text { HC IVs } \\
n=10 \\
\mathrm{n}(\%)\end{array}$ \\
\hline \multicolumn{6}{|l|}{ Essential NB care } \\
\hline & Clean blades & 4 & 2 & $6(100)$ & $10(100)$ \\
\hline & Cord ties/ligatures & 1 & 1 & $2(33.3)$ & $5(50)$ \\
\hline & Tetracycline ointment & 4 & 2 & $6(100)$ & $10(100)$ \\
\hline & Prevention of mother to child transmission of HIV & 4 & 2 & $6(100)$ & $10(100)$ \\
\hline & Weighing scale & 4 & 2 & $6(100)$ & $9(90)$ \\
\hline & Referral guidelines & 2 & 0 & $2(33.3)$ & $7(70)$ \\
\hline Overall mean score & Essential newborn care & $3.2(80.0)$ & $1.5(75.0)$ & $4.7(78.3)$ & $8.5(85)$ \\
\hline \multicolumn{6}{|l|}{ Resuscitation } \\
\hline & Neonatal resuscitation algorithm & 2 & 2 & $4(66.7)$ & $7(70)$ \\
\hline & Resuscitation area with heat lamp/source & 2 & 1 & $3(50.0)$ & $5(50)$ \\
\hline & Ventilation Bag & 4 & 2 & $6(100)$ & $9(90)$ \\
\hline & Mask (Term \& preterm) & 4 & 2 & $6(100)$ & $9(90)$ \\
\hline & Suction device & 4 & 2 & $6(100)$ & $10(100)$ \\
\hline & Pulse oximeter with a probe & 2 & 1 & $3(50.0)$ & $6(60)$ \\
\hline Overall mean score & Resuscitation & $3(75.0)$ & $1.7(85.0)$ & $4.7(78.3)$ & $7.7(77)$ \\
\hline \multicolumn{6}{|c|}{ Infection control and management + Convulsions } \\
\hline & Water \& soap/hand sanitizer & 4 & 2 & $6(100)$ & $10(100)$ \\
\hline & 7.1\% Chlorhexidine for cord care & 0 & 0 & $0(00)$ & 00 \\
\hline & C-Reactive protein testing & 1 & 0 & $1(16.7)$ & 00 \\
\hline & Stethoscope & 4 & 2 & $6(100)$ & $8(80)$ \\
\hline & Disposable gloves & 4 & 2 & $6(100)$ & $6(60)$ \\
\hline & Lancets (neonatal size) & 0 & 0 & $0(00)$ & 00 \\
\hline & Thermometer & 3 & 2 & $5(83.3)$ & $9(90)$ \\
\hline & Multi-function monitors & 2 & 0 & $2(33.3)$ & 00 \\
\hline & IV Cannulas & 4 & 2 & $6(100)$ & $8(80)$ \\
\hline & IV giving sets/tubing & 4 & 2 & $6(100)$ & $7(70)$ \\
\hline & Newborn weighing scale & 4 & 2 & $6(100)$ & $10(100)$ \\
\hline & Inj. Gentamycin & 0 & 2 & $2(33.3)$ & $8(80)$ \\
\hline & Inj. Ampicillin/penicillin & 2 & 2 & $4(66.7)$ & $10(100)$ \\
\hline & Glucometer & 4 & 0 & $4(66.7)$ & $5(50)$ \\
\hline & Glucose test strips & 1 & 0 & $1(16.7)$ & $5(50)$ \\
\hline & Anticonvulsant-Phenobarbitone & 4 & 2 & $6(100)$ & $7(70)$ \\
\hline & Infusion pump & 0 & 0 & $0(00)$ & 00 \\
\hline & Burettes & 2 & 2 & $4(66.7)$ & 00 \\
\hline & Dextrose 10\% & 2 & 2 & $4(66.7)$ & 00 \\
\hline & Guidelines for referral & 2 & 0 & $2(33.3)$ & $5(50)$ \\
\hline Overall & Overall infection control, management + Convulsions & $2.4(60.0)$ & $1.2(60.0)$ & $3.6(60.0)$ & $4.9(49)$ \\
\hline
\end{tabular}

practice KMC. In addition, only about half (3 hospitals and 4 HCIVs) of the health facilities had phototherapy machines for care of jaundiced newborn babies.

\section{Feeding of sick and small newborn babies}

The overall score for feeding of sick and small babies was about $50 \%$ in HCIVs and $67 \%$ in hospitals, and this was similar between public (67\%) and PNFP (65\%) hospitals (Table 3). The lancets, glucose test strips, breast pumps and referral guidelines were lacking in almost all health facilities.

Characteristics of participants for the exit interview

A total of 201 mothers (166 from public and 35 from PNFP health facilities) were interviewed during exit interviews. There were significantly younger mothers (mean age 21.4 years $\mathrm{SD} \pm 4.4$ ) whose HRBs were admitted to the PNFP hospitals, compared to those in public 
Table 3 (continued)

\begin{tabular}{|c|c|c|c|c|c|}
\hline Immediate PNC & Items/requirements & $\begin{array}{l}\text { Public hospitals } \\
n=4\end{array}$ & $\begin{array}{l}\text { PNFPs hospitals } \\
n=2\end{array}$ & $\begin{array}{l}\text { All hospitals } \\
n=6(\%)\end{array}$ & $\begin{array}{l}\text { HCIVs } \\
n=10 \\
\mathrm{n}(\%)\end{array}$ \\
\hline \multicolumn{6}{|l|}{ Feeding } \\
\hline & Water \& soap/sanitizer & 4 & 2 & $6(100)$ & $10(100)$ \\
\hline & NB weighing scale & 4 & 2 & $6(100)$ & $10(100)$ \\
\hline & Tape measure in NSCU & 3 & 2 & $5(83.3)$ & $6(60)$ \\
\hline & IV cannulas & 4 & 2 & $6(100)$ & $10(100)$ \\
\hline & Burettes & 2 & 2 & $4(66.7)$ & $0(00)$ \\
\hline & Dextrose-10\% & 2 & 2 & $4(66.7)$ & $0(00)$ \\
\hline & Ringers Lactate & 4 & 2 & $6(100)$ & $9(90)$ \\
\hline & Nasal gastric tube- neonatal size & 4 & 2 & $6(100)$ & $4(40)$ \\
\hline & Syringes/cups for feeding & 4 & 2 & $6(100)$ & $4(40)$ \\
\hline & Lancets & 0 & 0 & $0(00)$ & 00 \\
\hline & Glucometer & 4 & 0 & $4(66.7)$ & $5(50)$ \\
\hline & Glucose test strips & 1 & 0 & $1(16.7)$ & $5(50)$ \\
\hline & Small \& Sick newborn feeding guidelines & 4 & 2 & $6(100)$ & $5(50)$ \\
\hline & Breast pumps & 0 & 0 & 00 & 00 \\
\hline & Referral guidelines & 0 & 0 & 00 & 00 \\
\hline Overall & Feeding & $2.7(67.5)$ & $1.3(65.0)$ & $4(66.7)$ & $4.9(49)$ \\
\hline \multicolumn{6}{|c|}{ Preterm \& Hypothermia care } \\
\hline & Incubator or radiant warmer & 4 & 2 & $6(100)$ & $6(60)$ \\
\hline & KMC bed/chair & 1 & 0 & $1(16.7)$ & 00 \\
\hline & IV Aminophyline & 4 & 2 & $6(100)$ & $6(60)$ \\
\hline & CPAP & 1 & 1 & $2(33.3)$ & $2(20)$ \\
\hline & Phototherapy machine & 2 & 1 & $3(50.0)$ & $4(40)$ \\
\hline & Surfactant & 0 & 0 & 00 & 00 \\
\hline & Ear muffs/Earplugs for sound control & 0 & 0 & 00 & 00 \\
\hline & Cyclic lights or light reducing goggles & 0 & 0 & 00 & 00 \\
\hline Overall & Overall Preterm \& Hypothermia care & $1.5(37.5)$ & $0.8(40.0)$ & $2.3(38.3)$ & $1.8(18)$ \\
\hline
\end{tabular}

facilities, $p=0.008$ ) (Table 4). However, there was no difference in the period babies spent in the SNCU, with an average duration of about 5.3 days $\mathrm{SD} \pm 4.3$ in public hospitals compared to 4.9 days $\mathrm{SD} \pm 2.3$ in PNFP hospitals, $p=0.552$. Similarly, there was no difference in the diagnosis captured on the discharge forms. Most babies had a diagnosis of asphyxia (37\% in public facilities and $43 \%$ in PNFP hospitals) followed by preterm/LBW (28\% and $26 \%$ respectively, $p=0.971$ ).

\section{Client experience and satisfaction with service provision for high risk newborn babies}

Overall, client satisfaction with the services provided, and satisfaction with waiting time, health facility cleanness, and providers' attitudes were over 90\% in PNFP hospitals, significantly higher compared to public hospitals $(p<0.05)$ (Table 5). However, satisfaction with privacy was not significantly different in the two settings $(p=0.303)$.
The results further revealed that counselling on the prognosis of baby's condition, and on newborn danger signs was done for all mothers in PNFP hospitals

Table 4 Description of participants for exit interviews

\begin{tabular}{llll}
\hline Participant characteristics & Public HFs & PNFPs & p-value \\
\hline & $N=166$ & $N=35$ & $N=201$ \\
Average age of mother (SD) & $24.1(5.4)$ & $21.4(4.4)$ & $0.008^{* *}$ \\
Age of baby in days (SD) & $5.3(4.3)$ & $4.9(2.3)$ & 0.552 \\
Male Sex & 57.1 & 41.2 & 0.092 \\
Average birth weight (SD) & $2.6(0.8)$ & $2.2(0.6)$ & $0.006^{* *}$ \\
Diagnosis on discharge form & & & 0.971 \\
Asphyxia (difficulty in breathing) & $62(37.3)$ & $15(42.9)$ & \\
Preterm/LBW & $46(27.7)$ & $9(25.7)$ & \\
Neonatal infection & $32(19.3)$ & $6(17.1)$ & \\
Convulsions & $3(1.8)$ & $0(0.0)$ & \\
Jaundice & $10(6.0)$ & $3(8.6)$ & \\
Others & $13(7.8)$ & $2(5.7)$ &
\end{tabular}


Table 5 Client satisfaction with health care services, knowledge of neonatal danger signs, counselling on newborn illness, and follow up care plans

\begin{tabular}{|c|c|c|c|}
\hline Variables & $\begin{array}{l}\text { Public HFs } \\
N=166(\%)\end{array}$ & $\begin{array}{l}\text { PNFPs } \\
N=35 \text { (\%) }\end{array}$ & $p$-value \\
\hline \multicolumn{4}{|l|}{ Client satisfaction } \\
\hline Overall satisfaction & $121(72.9)$ & $32(91.4)$ & 0.017 \\
\hline Mean Waiting time (minutes) & $42.5(85.8)$ & $16.9(9.4)$ & 0.075 \\
\hline Satisfaction with waiting time & $109(65.7)$ & $34(97.1)$ & $<0.001$ \\
\hline Cleanness & $117(70.5)$ & $35(100.0)$ & $<0.001$ \\
\hline Privacy & $117(70.5)$ & $28(80.0)$ & 0.303 \\
\hline Time given & $133(80.1)$ & $35(100.0)$ & 0.002 \\
\hline Respect by providers & $117(70.5)$ & $33(94.3)$ & 0.002 \\
\hline \multicolumn{4}{|l|}{ Counselling } \\
\hline One on one about condition of baby & $142(85.5)$ & $35(100.0)$ & 0.010 \\
\hline Prognosis/possible complications & $122(73.5)$ & $35(100.0)$ & $<0.001$ \\
\hline Danger signs & $109(65.8)$ & $35(100.0)$ & $<0.001$ \\
\hline Nutrition & $130(78.3)$ & $35(100.0)$ & 0.001 \\
\hline Breast feeding & $153(92.2)$ & $35(100.0)$ & 0.130 \\
\hline Care at home & $139(83.6)$ & $35(100.0)$ & 0.005 \\
\hline When to come back for review & $152(91.6)$ & $35(100.0)$ & 0.136 \\
\hline Family planning & $97(58.4)$ & $21(60.0)$ & 1.000 \\
\hline Husband involved during counselling & $85(51.2)$ & 31 (88.6) & $<0.001$ \\
\hline \multicolumn{4}{|l|}{ Knowledge of newborn danger signs } \\
\hline Able to mention two danger signs & $83(50.0)$ & $10(28.6)$ & 0.021 \\
\hline \multicolumn{4}{|l|}{ Baby examined after delivery } \\
\hline Examined & $162(97.6)$ & $35(100.0)$ & 1.000 \\
\hline After how long baby is examined & & & 0.001 \\
\hline$<1 \mathrm{~h}$ & $118(71.1)$ & $35(100.0)$ & \\
\hline $1-6 h$ & $30(18.1)$ & $00(0.0)$ & \\
\hline$>6 \mathrm{~h}$ & $18(10.8)$ & $00(0.0)$ & \\
\hline Frequency of examining baby & & & 0.884 \\
\hline Once a day & $10(6.1)$ & $01(2.8)$ & \\
\hline Twice a day & $151(90.9)$ & $34(97.1)$ & \\
\hline Sometimes/not daily & $5(3.0)$ & $00(0.0)$ & \\
\hline \multicolumn{4}{|l|}{ Immunization } \\
\hline Baby immunized before discharge & $134(81.0)$ & $26(74.3)$ & 0.352 \\
\hline \multicolumn{4}{|l|}{ Money paid, supplies/medicines bought } \\
\hline Bought medicines/supplies outside HF & $87(52.7)$ & $10(29.4)$ & 0.013 \\
\hline Paid money to provider & $46(27.9)$ & $10(29.4)$ & 0.856 \\
\hline Median amount paid (UG shillings) & 20,000 & 100,000 & \\
\hline
\end{tabular}

compared to $74 \%$ and $65.8 \%$ respectively in public facilities. However, only $29 \%$ of mothers in PNFP facilities were able to mention at least two newborn danger signs compared to $50 \%$ of those in public facilities. The proportion of mothers counseled on family planning before discharge $(60 \%)$ was similar in both settings.

All babies were reportedly examined within one hour after birth in PNFP hospitals compared to only $71 \%$ in public health facilities. In fact, almost all babies were examined at least twice per day in both settings.
However, there were missed opportunities for immunization of the babies before discharge in both public (19\%) and PNFP (26\%) settings.

\section{Discussion}

In this study we found that overall health facility readiness to care for HRBs was insufficient with the lowest preparedness within the area of preterm care and hypothermia where the scores were 38\% in hospitals and $18 \%$ in HCIVs. Health facilities also scored low in readiness 
for the control and management of infections and convulsions. The readiness was highest within the fields of essential routine newborn care and neonatal resuscitation followed by feeding. The results are not surprising given the Ugandan Ministry of Health's efforts focusing on essential routine newborn care and resuscitation through the HBB-plus intervention program throughout the country. Previous studies in the country also reported facility readiness to have been consistently highest for essential newborn care [20,37].

The samples were small for any generalization but there was a tendency for readiness to be better in PNFP facilities where there were fewer clients compared to public health facilities. The supply chain of PNFPs is different from that of public facilities, and given that clients pay for services at these institutions, they may be able to demand for better services. Client satisfaction was also notably better in the PNFP hospitals. However, there are still challenges of quality of service provision in both settings. The human resource in both public and PNFPs facilities require attention if the quality of services is to improve. For instance, the lack of neonatal nurses for care of neonates deserves urgent attention. The newborn to midwife ratio of 1:20 in NSCU compared to the 1:4 in high income countries is appalling (7). Moreover these health providers are the same who deliver mothers in maternity units.

There were missed opportunities for immunization of the vulnerable babies before discharge. These could also be explained by the lack of vaccines, and/or lack of knowledge on when to vaccinate sick and small newborn babies [38, 39]. In addition, there were fewer mothers in PNFP facilities compared to public facilities who could mention at least two danger signs despite most of the mothers reporting to have been counseled, pointing to limited skills in counselling. Counselling of clients requires skilled professionals in that discipline. However, clinicians including nurses, though expected to undertake that role, are not experts in counselling and therefore may not consider it as a priority responsibility especially when they are overwhelmed by patient numbers. The HIV/AIDS service provision includes use of professional counsellors and this has notably improved the client's awareness of the disease process and outcomes as well as adherence to medication [40]. Nonetheless, this is lacking in other areas of service provision like the maternal and newborn health. The MoH should pick lessons and consider recruitment of more staff particularly midwives, neonatal nurses, and counsellors in maternal and newborn health as it is currently doing for HIV/AIDs services.

The study findings showed that a significant proportion of babies were not assessed within one hour after birth. This may further suggest a high workload among health care providers. Every newborn baby requires thorough assessment in order to identify emergency complications that can be addressed, including failure to breath and hypothermia [11].

Notably, facility readiness for feeding was relatively good in all hospitals. Hospitals encouraged mothers to breastfeed, and used feeding cups or nasal gastric tubing when the babies were not able to suckle. The scores in this area could be explained by the recent concerted efforts of the PTBi project in the six hospitals through the clinical trainings and mentorships that prioritized monitoring and feeding of the sick and small babies in the NSCU. The project imparted knowledge and skills as well as provision of guidelines for each health facility. However, there were limited equipment and supplies provided at the beginning of the project [34] and these did not include items like breast milk pumps and infusion pumps. Feeding of vulnerable newborn babies may prove to be challenging due to the stressful situations mothers may be experiencing but also given the complications of the baby that may not allow suckling for some time. Notably, malnutrition is one of the risk factors for NDD in those babies [13]. Midwives require skills in this area in order to offer nutrients to the babies, and support the mothers in participating in effective and adequate nutrition of their babies.

Readiness for care of the preterm and LBW babies who are more likely to develop NDD is still lagging behind despite PTBi previous work in those facilities, and requires more attention. This implies that care for preterm babies elsewhere in district hospitals may be even worse, as evidenced by very low readiness scores for the HCIVs. There is considerable evidence that KMC improves not only survival of these neonates but also reduces risk of NDD [13, 41]. Moreover, practice of $\mathrm{KMC}$ is known to be challenging especially if the environment is not conducive [42]. Investment in $\mathrm{KMC}$ beds and chairs should be considered for district hospitals and HCIVs with designated KMC units. Furthermore, national guidelines for the NSCU in terms of lighting and sound control should be developed. There is evidence that highlights the relationship of the neonatal intensive care unit environment and NDD of vulnerable babies [43] and therefore needs to be addressed.

The results revealed that most cases admitted in newborn care units were due to asphyxia despite high facility readiness in resuscitation. This calls for urgent attention and investment in improving intrapartum care, particularly emergency obstetric and neonatal care. Evidence shows that availability of quality obstetric and neonatal care in countries with limited resources could prevent more than $50 \%$ of neonatal 
deaths and still births, and translate into better neurodevelopmental outcomes of the survivors $[44,45]$.

There are a number of policy implications of the findings from this study: The results reveal several readiness challenges in both hospital and HCIV facilities. The findings also showed that there are HRBs managed at HCIV level. There is therefore need for more investment in NSCU for comprehensive care of the sick and small newborn babies, beyond essential newborn care and resuscitation, in both hospital and HCIVs. This will improve quality service provision, reduce neonatal mortality and contribute to better neurodevelopment of infants. Resources are urgently needed, including human resource (numbers and skills mix: midwives, neonatal nurses as well as counsellors in maternal and newborn health), commodities and guidelines particularly for the care of preterm babies. In addition, health systems should be strengthened so as to provide quality intrapartum care/EmOC in order to reduce the numbers of asphyxia cases, and hence reduced burden of NDD.

\section{Study limitations}

There are some limitations to the study: We were unable to do knowledge and skills assessment of health workers, yet availability of equipment and supplies may not translate into quality service provision without skilled human resource. We did not also assess for availability of vaccines given within the first week after birth which is a main factor for reducing early infections. In addition, few hospitals were included in the study limiting the generalizability of the study findings. Furthermore, exit interviews have an inherent weakness of social desirability bias, and mothers may have had recall limitations after a stressful child birth experience. However, the study findings are still important in informing policy and programming for improved service delivery aimed at transforming care for improved neurodevelopment of the most vulnerable newborn babies.

\section{Conclusion}

The results revealed low health facility readiness scores in both hospitals and higher level health centres (HCIVs), particularly for the care of preterm babies. In addition, the main cause of admission to the NSCU was birth asphyxia. There is therefore need for more investment for comprehensive emergency obstetric care and care of the sick and small newborn babies in both hospital and HCIVs. This will contribute to improvement in the quality of maternal and neonatal care, reduce neonatal mortality, and result in better neurodevelopment of infants.

\section{Abbreviations}

AIDS: Acquired immune-deficiency syndrome; ANC: Antenatal care; CPAP: Continuous positive airway pressure; ECD: Early child development; EmoC: Emergency obstetric care; EmoNC: Emergency obstetric and neonatal care; HBB: Helping babies breathe; HCIVs: Health centre IVs; HDREC: Higher degrees, research and ethical council; HIV: Human immunodeficiency virus; HRB: High risk newborn babies; KMC: Kangaroo mother care; LBW: Low birth weight; LICs: Low income countries; LMICs: Low and middle income countries; MoH: Ministry of Health; NDD: Neurodevelopmental disability; NSCU: Neonatal special care unit; PNFP: Private Not for Profit; PTBi: Preterm Birth Initiative; QoC: Quality of care; RRH: Regional Referral Hospital; SARA: Service availability and readiness assessment; WHO: World Health Organization.

\section{Acknowledgement}

We are grateful to the health facilities which participated in this study, the health workers who provided the required information, and the mothers who were interviewed. In addition, we thank the research assistants who supported the data collection.

\section{Authors' contributions}

GN1 conceptualized the study, drafted and led the writing of the manuscript. JKT, PW, HH, GN2 provided substantial contributions to the conceptualization and design of the study. PM and GN1 acquired, analyzed and interpreted the data. JKT, PW, HH, GN2, CN and AKM supported interpretation of data, critically reviewed and revised the manuscript for important intellectual content. All authors contributed to the writing, and reviewed and approved the final version of the manuscript.

Funding

This work was funded under Makerere University —SIDA research collaboration programme (project number Sida 344), which is greatly appreciated.

\section{Availability of data and materials}

The datasets generated and analyzed during the current study are not publicly available due to the fact that some of the data were obtained from government of Uganda health facilities, but are available from the corresponding author on reasonable request.

\section{Declarations}

\section{Ethics approval and consent to participate}

All methods were performed in accordance with the relevant guidelines and regulations. This study was approved by the Makerere University School of Health Sciences Research and Ethics Committee (SHSREC Ref: 2017-011), and the Uganda National Council of Science and Technology (Ref. SS4600). Written informed consent was obtained from all study participants.

\section{Consent for publication}

Not applicable.

\section{Competing interest}

All authors declare no conflict of interest.

\section{Author details \\ ${ }^{1}$ Department of Health Policy, Planning and Management, School of Public Health, College of Health Sciences, Makerere University, Mulago Hill Road, P. O. Box 7072, Kampala, Uganda. ${ }^{2}$ Department of Nursing, School of Health Sciences, College of Health Sciences, Makerere University, Kampala, Uganda. ${ }^{3}$ Astrid Lindgren Children's Hospital, Karolinska University Hospital, Stock- holm, Sweden. ${ }^{4}$ Health Systems \& Policy, Department of Global Public Health, Karolinska Institutet, Stockholm, Sweden. ${ }^{5}$ Department of Clinical Science, Intervention and Technology (CLINTEC), Karolinska Institutet, Stockholm, Sweden. ${ }^{6}$ Department of Paediatrics and Child Health, School of Medicine, College of Health Sciences, Makerere University, Kampala, Uganda. ${ }^{7}$ Depart- ment of Community Health and Behavioral Sciences, School of Public Health, College of Health Sciences, Makerere University, Kampala, Uganda. ${ }^{8}$ School of Medicine, Kabale University, Kabale, Uganda.}

Received: 18 August 2021 Accepted: 28 February 2022

Published online: 05 March 2022 


\section{References}

1. UN-IGME. Levels and Trends in Child Mortality: Report 2018, Estimates developed by the UN Inter-agency Group for Child Mortality Estimation. http://www.childmortality.org/. 2018.

2. WHO U World Bank Group. Nurturing care for early childhood development: a framework for helping children survive and thrive to transform health and human potential. Geneva: World Health organization; 2018.

3. Maulik PK, Darmstadt GL. Childhood disability in low-and middle-income countries: overview of screening, prevention, services, legislation, and epidemiology. Pediatrics. 2007;120(Supplement 1):S1-55.

4. Goldstein S, Reynolds CR. Handbook of Neurodevelopmental and Genetic Disorders in Children, 2/e: Guilford Press; 2010.

5. WHO. Survive and thrive: transforming care for every small and sick newborn. Geneva: World Health Organization; 2019. 20199789241515887.

6. WHO. Standards for improving quality of care for small and sick newborns in health facilities. Geneva: World Health Organization; 2020. Licence: CC BY-NC-SA 3.0 IGO

7. Moxon SG, Lawn JE, Dickson KE, Simen-Kapeu A, Gupta G, Deorari A, et al. Inpatient care of small and sick newborns: a multi-country analysis of health system bottlenecks and potential solutions. BMC Pregnancy Childbirth. 2015;15(2):S7.

8. Bhutta ZA, Das JK, Bahl R, Lawn JE, Salam RA, Paul VK, et al. Can available interventions end preventable deaths in mothers, newborn babies, and stillbirths, and at what cost? The Lancet. 2014;384(9940):347-70.

9. Mwaniki MK, Atieno M, Lawn JE, Newton CR. Long-term neurodevelopmental outcomes after intrauterine and neonatal insults: a systematic review. The Lancet. 2012;379(9814):445-52.

10. March of Dimes P, Save the Children, WHO. In: Howson CP, Kinney MV, Lawn JE, editors. Born Too Soon: The Global Action Report on Preterm Birth. Geneva: World Health Organization; 2012.

11. American Academy of Pediatrics. Helping Babies Breathe http://www helpingbabiesbreathe.org/2013 [cited 2013 June 29, 2013].

12. Arya S, Naburi H, Kawaza K, Newton S, Anyabolu CH, Bergman N, et al. Immediate" Kangaroo Mother Care" and Survival of Infants with Low Birth Weight. N Engl J Med. 2021;384(21):2028-38.

13. Namazzi G, Tumwine JK, Hildenwall H, Ndeezi G, Mubiri P, Hanson C, et al. Neurodevelopmental outcomes of preterm babies during infancy in Eastern Uganda: a prospective cohort study. Glob Health Action. 2020;13(1):1820714

14. Kayom VO, Kakuru A, Kiguli S. Newborn Care Practices among MotherInfant Dyads in Urban Uganda. Int J Pedia. 2015;2015:8. Article ID 815938. https://doi.org/10.1155/2015/815938.

15. Aliganyira P, Kerber K, Davy K, Gamache N, Sengendo NH, Bergh A-M. Helping small babies survive: an evaluation of facility-based Kangaroo Mother Care implementation progress in Uganda. Pan Afr Med J. 2014;19:37. https://doi.org/10.11604/pamj.2014.19.37.3928.

16. Helfinstein S, Jain M, Ramesh BM, Blanchard J, Kemp H, Gothalwal $\checkmark$, et al. Facilities are substantially more influential than care providers in the quality of delivery care received: a variance decomposition and clustering analysis in Kenya, Malawi and India. BMJ Global Health. 2020;5(8):e002437.

17. Donabedian A. The quality of care: how can it be assessed? JAMA 1988:260(12):1743-8

18. Kruk ME, Chukwuma A, Mbaruku G, Leslie HH. Variation in quality of primary-care services in Kenya, Malawi, Namibia, Rwanda, Senegal, Uganda and the United Republic of Tanzania. Bull World Health Organ. 2017:95(6):408

19. Namazzi G, Waiswa P, Nakakeeto M, Nakibuuka VK, Namutamba S Najjemba M, et al. Strengthening health facilities for maternal and newborn care: experiences from rural eastern Uganda. Glob Health Action. 2015;8(1):24271

20. Morgan MC, Spindler $H$, Nambuya $H$, et al. Clinical cascades as a novel way to assess physical readiness of facilities for the care of small and sick neonates in Kenya and Uganda. PloS one. 2018;13(11):e0207156.

21. Dickson KE, Simen-Kapeu A, Kinney MV, Huicho L, Vesel L, Lackritz E, et al. Every Newborn: health-systems bottlenecks and strategies to accelerate scale-up in countries. The Lancet. 2014;384(9941):438-54
22. Lawn JE, Mwansa-Kambafwile J, Horta BL, Barros FC, Cousens S. "Kangaroo mother care" to prevent neonatal deaths due to preterm birth complications. Int J Epidemiol. 2010;39(Suppl 1):i144-54.

23. Conde-Agudelo A, Belizan JM, Diaz-Rossello J. Kangaroo mother care to reduce morbidity and mortality in low birthweight infants. Cochrane Database Syst Rev. 2011(3):CD002771.

24. Bee M, Shiroor A, Hill Z. Neonatal care practices in sub-Saharan Africa: a systematic review of quantitative and qualitative data. J Health Popul Nutr. 2018:37(1):1-12.

25. WHO UNICEF. Every newborn: an action plan to end preventable deaths. Geneva:WHO; 2014. (http://www.everynewborn.org/Documents/Fullaction-plan-EN.pdf 2016).

26. Mason E, McDougall L, Lawn JE, Gupta A, Claeson M, Pillay Y, et al. From evidence to action to deliver a healthy start for the next generation. The Lancet. 2014;384(9941):455-67.

27. Ganz ML, Tendulkar SA. Mental health care services for children with special health care needs and their family members: prevalence and correlates of unmet needs. Pediatrics. 2006;117(6):2138-48.

28. Mbonye AK, Sentongo M, Mukasa GK, Byaruhanga R, Sentumbwe-Mugisa O, Waiswa P, et al. Newborn survival in Uganda: a decade of change and future implications. Health Policy Plan. 2012;27(3):iii104-17.

29. UBOS. Uganda Bureau of Statistics (UBOS) and ICF International Inc. 2006. Uganda Demographic and Health Survey. Kampala, Uganda: UBOS and Calverton. Maryland: ICF International Inc; 2006. p. 2006.

30. UBOS. Uganda Demographic And Health Survey 2016. Calverton, Maryland, USA: U. B. O. S. U. A. M. Orc., 2016.

31. Namazzi G, Hildenwall H, Mubiri P, Hanson C, Nalwadda C, Nampijja M, et al. Prevalence and associated factors of neurodevelopmental disability among infants in eastern Uganda: a population based study. BMC Pediatr. 2019;19(1):379

32. MUCHAP. Annual Progress Report, 2015. Makerere University Centre for Health \& Population Research (MUCHAP) operating Iganga-Mayuge Health Demographic Surveillance Site-Uganda (IMHDSS). Makerere University, 2015.

33. $\mathrm{MoH}$. National health facility master list. A complete list of all health facilities in Uganda. Kampala, Uganda: Division of Health Information, Ministry of Health, Uganda 2017.

34. Walker D, Otieno P, Butrick E, Namazzi G, Achola K, Merai R, et al. Effect of a quality improvement package for intrapartum and immediate newborn care on fresh stillbirth and neonatal mortality among preterm and low-birthweight babies in Kenya and Uganda: a cluster-randomised facility-based trial. Lancet Glob Health. 2020;8(8):e1061-70.

35. Moxon SG, Guenther T, Gabrysch S, Enweronu-Laryea C, Ram PK, Niermeyer S, et al. Service readiness for inpatient care of small and sick newborns: what do we need and what can we measure now? Journal Glob Health. 2018;8(1):010702.

36. Peter Waiswa GN, Paul Mubiri, Darius Kajjo,. Preterm Birth Initiative Progress report for 2016. 2016.

37. Narayanan I, Nsungwa-Sabiti J, Lusyati S, Rohsiswatmo R, Thomas N Kamalarathnam CN, et al. Facility readiness in low and middle-income countries to address care of high risk/small and sick newborns. Maternal health, neonatology and perinatology. 2019;5(1):1-14.

38. D'Angio CT. Active immunization of premature and low birth-weight infants. Pediatr Drugs. 2007;9(1):17-32.

39. Malande OO, Munube D, Afaayo RN, Annet K, Bodo B, Bakainaga A, et al. Barriers to effective uptake and provision of immunization in a rural district in Uganda. PloS one. 2019;14(2):e0212270.

40. MoH. Uganda National Policy Guidelines for HIV Counselling and Testing Ministry of Health, Uganda, 2005.

41. Conde-Agudelo A, Díaz-Rossello JL. Kangaroo mother care to reduce morbidity and mortality in low birthweight infants. Cochrane Database Syst Rev. 2016;2016(8):CD002771.

42. Jamali QZ, Shah R, Shahid F, Fatima A, Khalsa S, Spacek J, et al. Barriers and enablers for practicing kangaroo mother care (KMC) in rural Sindh, Pakistan. PloS one. 2019;14(6):e0213225.

43. Santos J, Pearce SE, Stroustrup A. Impact of hospital-based environmental exposures on neurodevelopmental outcomes of preterm infants. Curr Opin Pediatr. 2015;27(2):254. 
44. Grady K, Ameh C, Adegoke A, Kongnyuy E, Dornan J, Falconer T, et al. Improving essential obstetric and newborn care in resource-poor countries. J Obstet Gynaecol. 2011;31(1):18-23.

45. Lee AC, Kozuki N, Blencowe H, Vos T, Bahalim A, Darmstadt GL, et al. Intrapartum-related neonatal encephalopathy incidence and impairment at regional and global levels for 2010 with trends from 1990. Pediatr Res. 2013:74(S1):50.

\section{Publisher's Note}

Springer Nature remains neutral with regard to jurisdictional claims in published maps and institutional affiliations.

- fast, convenient online submission

- thorough peer review by experienced researchers in your field

- rapid publication on acceptance

- support for research data, including large and complex data types

- gold Open Access which fosters wider collaboration and increased citations

- maximum visibility for your research: over 100M website views per year

At BMC, research is always in progress.

Learn more biomedcentral.com/submissions 